\title{
Chromosomal Translocation
}

National Cancer Institute

\section{Source}

National Cancer Institute. Chromosomal Translocation. NCI Thesaurus. Code C3420.

A genetic exchange where a piece of one chromosome is transfered to another chromosome. 